\title{
Analysis of the Causes of Low Fertility Rate and Study of Family Social Security System against the Background of "Universal Two-Child" Policy
}

$$
\text { Qian Yang }{ }^{1, a} \text {, Liu Xinran }{ }^{2, b, *}
$$

1Department of Sociology, School of Law, Changchun University of Science and Technology, Changchun, Jilin, China

${ }^{2}$ Department of Sociology, School of Law, Changchun University of Science and Technology, Changchun, Jilin, China

a5236232@qq.com, b591863206@qq.com

${ }^{*}$ Qian Yang

Keywords: The "Universal Two-Child Policy", Low fertility rate, Family social security.

\begin{abstract}
The main causes of low fertility rates analyzed,which are heavy economic burdens as well as stress to families, and there is no corresponding family social security system. We compared with the existing fertility system in China and the family social security system in Western developed countries, and translated the official data on the birth rate of newborns since the implementation of the Two-child policy in China, in order to propose and improve Chinese family social security system.
\end{abstract}

\section{“全面二孩”政策背景下，低生育率的成因分析及家庭社会保障制度研究}

\author{
杨茜 ${ }^{1, a,{ }^{*},}$, 刘欣然 $2, b$ \\ ${ }^{1}$ 长春理工大学法学院社会学系, 长春, 吉林, 中国 \\ 2 长春理工大学法学院社会学系, 长春, 吉林, 中国 \\ a5236232@qq.com, b591863206@qq.com \\ *杨茜
}

关键词: 全面二孩; 低生育率; 家庭社会保障

中文摘要：2016年1月1日起，我国开始全面实施二孩政策，两年时间过去了，我国新生儿的 出生率总体处于下降趋势。通过分析, 认为造成低生育率的主要原因之一, 是我国没有出台 相应的家庭社会保障制度，生育二孩给家庭带来沉重的经济负担和精神压力。因此本文根据 我国已有的生育制度，并参照西方发达国家家庭社会保障制度，提出完善我国家庭社会保障 制度的对策建议。

\section{1. 引言}

2013年12月28日，十二届全国人大常委会第六次会议表决通过《关于调整完善生育政策 的决议》，标志着“单独二孩”政策正式实施。2015年12月27日，全国人大常委会表决通过了 人口与计划生育法修正案，“全面二孩”，即所有夫妇，无论城乡、区域、民族，都可以生育 两个孩子的政策, 于2016年1月1日起正式实施。这是继2014年全国各省市陆续实施一方是独 
生子女的夫妇可以生育两个孩子的“单独二孩”政策之后，中国人口生育政策的又一次重大调 整。20世纪70年代末 80 年代初开始的“独生子女”政策让中国家庭走入了独生子女时代, 两次 “二孩”政策调整将推动中国家庭迈向“后独生子女时代”。

\section{2.“全面二孩”政策背景下的低生育率及成因分析}

无论是“独生子女”政策，还是“全面二孩”政策，都是通过人口结构的调整来解决社会发展 中遇到的问题。随着“独生子女”的父母逐渐步入老年阶段, 中国的老龄化程度将越来越严重, 为了解决中国未来的养老问题, 国家实行稳健的政策调整, “全面二孩”政策的实行刺激了中 国未来新生儿的出生率，不是集中于一段时间或长时间的“不反弹”。国家统计局发布的数据 显示, 2017 年我国出生人口为 1723 万人。其中, 二孩出生人数比 2016 年明显增加, 比重超过 一半，达到了 883 万人。但是，在“全面二孩”政策效果持续显现的同时，一孩的出生数量却呈 现了较多下降的趋势。除此之外, 2017 年比上一年减少了 63 万, 人口出生率比上一年下降了 $0.52 \%$, 达到 $12.43 \%$ 。那么为什么当国家放宽了生育政策, 仍不能遏制生育人口数量的下滑 趋势? 作者将从以下几个方面进行分析。

\section{1 高龄生育风险高}

近年来, 随着我国人口年龄结构的变化, 育龄妇女人数呈现逐年减少的趋势。同时, 随 着经济社会发展, 教育年限的延长, 女性求职就业的比例增加, 我国妇女初婚和初育年龄也 不断在推迟, 妇女生育意愿有所下降。2017年 15 岁至49岁育龄妇女人数比 2016 年减少 400 万人, 其中 20 至 29 岁生育旺盛期育龄妇女人数减少近 600 万人。

无论是生育一胎还是二孩，35岁以上女性流产、致畸等生育风险在逐年加大。从一胎的 生育周期开始到二胎出生结束, 女性扮演母亲角色的时间是较长的, 而且现在多数想要生育 二胎的家庭, 由于女性在工作岗位中的不利地位, 需要她们长时间的捆绑在岗位上之后, 才 能拥有较稳定的工作岗位和经济来源, 这时虽然拥有养育二胎的经济基础, 但是女性的年龄 普遍偏高, 也使得她们在生育后代时要面临更大的风险。

\section{2女性就业压力增大}

虽然“全面二孩”政策的实施是为了调整人口结构,解决我国老龄化的现实背景下家庭养老 问题, 但是也出现了不可避免的问题——女性就业压力增大。原本在市场经济下的职位竞争 中，女性相比男性稍显弱势，当“全面二孩”政策开放后，在人力资源市场里出现的现象是， 没结婚的女性, 生了一个孩子的女性比生育两个孩子的女性竞争力弱。企业在招聘的过程中 会潜意识里考虑企业成本问题，当一个女性生育两个孩子之后，除了法定休息的节假日之外， 企业还要负担女职工生育后代过程中的额外成本。不仅如此, 女性长时间离开工作岗位, 需 要重新适应工作环境, 要付出更多的努力, 也使得女性在职场中处于不利的地位。

\section{3“女性生育抚养价值感低”的观念驱使}

现代社会中衡量一个人在家庭中的价值往往以其社会经济价值作为最主要的衡量标准。 而在传统观念中, 女性在家庭中的主要角色是抚养后代、料理家务, 即主要以家庭事务为主, 男主外、女主内。因此, 在生育、抚育孩子的过程中, 女性为家庭舍弃自己本来可以在社会 职场中创造的经济价值, 将更多的精力和时间投入到抚育后代中。但是, 在社会普遍的价值 观念中, 多数人会认为女性在家庭中抚养孩子的价值比其在社会生产中的经济价值低。这就 间接否定了女性家务劳动的社会价值, 致使职业女性更想要创造更多的经济价值和社会价值。

\section{4 抚育成本高}

中国家庭抚育一个孩子的时间成本和经济成本普遍较高。随着社会市场经济的发展，劳 动力的生产也成为竞争的商品。如何培育优秀的人力, 则要依据每个家庭所付出的人力资本 
和经济资本等。有人曾经计算, 养育一个孩子从出生到长大成人, 需要付出 100 万元的经济资 本。如果按照现有的城镇平均收入水平, 差不多要付出一个双职工家庭近 10 年的纯收入。因 此, 对于普遍较高的抚育成本, 加之养育一个子女所付出的时间成本, 让很多家庭望而却步。

\section{5 托育服务配套缺失}

在中国的计划经济体制下，城镇的职工基本上都被单位制所覆盖，企业办社会，企业除 了是生产单位, 也是生活单位。城镇的单位为职工配备生活所需的多方面的福利, 例如单位 设立自己的诊所, 大型的国有企业往往有自己的附属医院、学校、托儿所等。女职工可以将 自己的子女送入职工托儿所, 解决职工工作和家庭的矛盾冲突, 既能正常工作, 也能兼顾照 顾子女。然而, 我国进入市场经济改革之后, 对于未满3岁的婴幼儿缺少配套的保障机制。因 此, 对于未满 3 岁的婴幼儿的照顾一般只局限于家庭, 对于经济条件较好的家庭可以雇佣家政, 普通家庭则主要通过老人照顾。而由于受到计划生育制度的影响, 我国现有的家庭结构是以 核心家庭为主，呈现“4-2-1”模式，即夫妻两人有四个老人和一个子女需要照顾。在我国“全面 二孩”政策背景下，则转变为“4-2-2”的家庭结构，对于中国普遍存在的双职工家庭，需要同时 照顾四个老人和两个子女, 往往没有足够的时间成本和经济成本, 如果没有配套的托育服务 体系，将很难实现普遍的家庭两孩的设想。

\section{3.我国现阶段的生育制度及对策建议}

\section{1 我国现阶段已有的生育制度和保障措施}

党的十八届五中全会会议决定: 坚持计划生育的基本国策, 完善人口发展战略, 全面实 施一对夫妇可生育两个孩子政策。积极开展应对人口老龄化行动。2015年10月29日, 中共全 会公报允许普遍二孩政策: 促进人口均衡发展。坚持计划生育的基本国策, 完善人口发展战 略。全面实施一对夫妇可生育两个孩子政策。提高生殖健康、妇幼保健、托幼等公共服务水 平。可以看出, “全面二孩”政策出台之后, 无论是从政策观念还是人民的实际生活中, 国家 都有为其作辅助保障的身影。但是, 与国外比较起来, 中国在这些保障方面, 没有通过立法 的形式, 做出强制性的法律来鼓励和保障家庭在生育和养育过程中面临的其他风险。在社会 层面上，也没有更多实质性的帮助或是服务来保障家庭在生育和养育过程中遇到的风险。

更多的导向是各地方政府根据本地的现实情况出台了一些辅助保障。比如, 江西省各级 妇幼保健院设立“高龄高危孕产妇门诊”, 广东省实施《女职工劳动保护特别规定办法》, 即 自2016年9月29日起, 广东省将女职工符合法律法规规定生育子女的奖励假, 从30天延长至 80 天, 也就是广东省女职工产假将由最少 128 天延长至最少 178 天。尽管各地方出台一些“办法” 或“条例”, 但是很多人却没有办法及时了解到相应的信息, 这也使得信息的传递效果和实际 效用十分有限。

\section{2 对完善我国家庭社会保障的对策建议}

\subsection{1 完善生育医疗制度和服务}

首先, 全面二孩政策实施后, 将面临较高比例高龄产妇生育风险问题, 因此应高度重视 高龄产妇健康体检, 提高高龄产妇生产及康复服务, 确保全面二孩政策实施后的母婴健康和 安全。其次, 儿科医生和医疗水平也应被重视。以往研究显示 2008 年全国儿科医生数为6.17 万, 平均每万名儿童拥有 2.6 名医生, 缺口超过 20 万人。结合 2013 年我国及各省儿科医生数, 计算缺口与供需比。以出生人口峰值量计算未来五年我国儿科医生缺口达198287人, 供需比 仅为 0.35 左右, 现有儿科医生数已远远不能满足“全面二孩”政策下的需求。面对儿科医生所处 的困境和资源的短缺, 国家应该从政策或立法层面做出适度的补助。重设“儿科”专业, 对儿 科医生增加补助和提高待遇都可以促进儿科医生的数量增长。最后, 对于孕妇和儿童的医疗 
保险的内容, 除了部分检查项目的医疗补贴和相应药品可报销的方式以外, 国家应该扩大更 高质量和更广范围的保障措施以减轻家庭的负担，进而鼓励更多的家庭生育后代。

\subsection{2 灵活配置产假}

在中国，孕妇的产假是一次性的，在产后的一段时间内，孕妇处于完全放假和脱离社会 的状态。我们可以借鉴澳大利亚的产假休放方式, 将固定的产假变得灵活, 在时间长度上有 一个明确的规定, 但是孕妇可以自由选择安排这些时间, 比如, 在近一百多天的产假中, 如 果觉得时间能够安排得当, 可以选择提前进入工作岗位, 但是只上半天班, 用这些时长来向 后累积, 最终休完完整的时长。借此, 母亲不仅能够安心照顾家庭, 也不用担心长时间与社 会脱轨, 需要花费更多的时间去适应和竞争。因此, 可以对我国现有的生育保险制度灵活调 整，通过建立法律法规的方式予以确定。

3.2 .3 建立托育服务机制

从宏观的角度来看，社会能够为家庭减轻一些生活负担，不仅仅是从一些鼓励性的政策 上产生效果, 公共服务的设立和基础设施的建立也能够为家庭提供便利。比如, 在社区中设 立托育中心, 由社区的社会工作者或志愿者负责社区内学生的接送和放学后的托管。在托育 中心社会工作者还可以开展社会工作的相关活动, 不仅能够减轻家庭负担, 同时促进孩子的 健康成长。除此之外, 还能够调动社区内部的资源, 通过居民和社区人员的互动, 增强居民 对社区的认同感、归属感。

\section{2 .4 降低教育支出}

从国外家庭福利制度中可以看出, 大多数国家鼓励生育的方式是减少家庭在养育过程中 的支出。那么在中国想要稳步提升新生儿的出生率, 应该切合我国的实际情况, 可以通过降 低教育支出减轻家庭负担, 比如延长义务教育的年限, 从幼儿阶段延伸至高中阶段, 为接受 高等教育的家庭提供更加普便的助学贷款制度, 同时出于公平公正的角度考虑, 应尽可能的 让所有的适龄学生享受到较均衡的教学资源。

\subsection{5 价值导向驱动}

国家在提倡“全面二孩”政策的同时，也应注重对公民价值的引导。提升妇女照顾家庭的 价值感, 比如通过家务劳动社会化的方式, 一方面, 对于经济条件较好的家庭, 可以通过家 务劳动外包, 雇佣家政等方式减轻妇女在照顾子女和家务劳动中的负担; 另一方面, 转变人 们的观念, 认为家务劳动不创造社会价值的旧思想, 将妇女为家庭所付出的劳动计量化, 等 同于女性在家庭外所付出的社会价值。与此同时, 改变“男主外, 女主内”的传统观念, 男性 在家庭中同样负有教育子女、承担家务的责任, 以此减轻女性在家庭中的劳动量。

\section{4. 结语}

我国要实现“全面二孩”的设想, 缓解老龄化的压力, 除了出台新的生育政策以外, 还应相 应出台保障生育的家庭社会保障制度, 以此缓解家庭在生育问题上的经济压力和精神负担。

\section{References}

[1] S. K. Goyal, An integrated inventory model for a single supplier-single customer problem, International Journal of Production Research, vol.15, pp. 107-111, 1977.

[2] Xiaotian Feng, Separate Two-Child: Prospects for Social Impact of Fertility Policy Adjustment, Journal of Chinses Academy of Governance, 2014, (5) :57-62. (in Chinese)

[3] Xiaotian Feng and Xiaotao Wang, The Change of "Universal Two-Child Policy " and Chinese Family Model from One-Child Family to Post-One-Child Family, Journey of Chinese Youth Social Science, 2016, (2) :47-53. (in Chinese) 
[4] Xiaotian Feng, Dudley Poston, and Xiaotao Wang, China's One - child Policy and the Changing Family, Journal of Comparative Family Studies, 2014, ( 45). (in Chinses)

[5] Yukai Du and Yi Liu, Maternal and Child Health Management[M]. Beijing: People's medical publishing house, 2014.

[6]Qiuxia Song, Fang Wang and Li Song, Pediatricians' Needs and Gap Budgets under the Universal Two-Child Policy, Chinese Journey of Health Policy, 2016, 9 (2) :65-70. (in Chinses) 